\title{
Immune Modulation by Adjuvants Combined with Diphtheria Toxoid Administered Topically in BALB/c Mice After Microneedle Array Pretreatment
}

\author{
Z. Ding, ${ }^{1,3}$ E. Van Riet, ${ }^{1}$ S. Romeijn, ${ }^{1}$ G. F. A. Kersten, ${ }^{2}$ W. Jiskoot, ${ }^{1}$ and J. A. Bouwstra ${ }^{1,4}$
}

Received December 26, 2008; accepted March 10, 2009; published online March 27, 2009

Purpose. In this study, modulation of the immune response against diphtheria toxoid (DT) by various adjuvants in transcutaneous immunization (TCI) with microneedle array pretreatment was investigated. Methods. TCI was performed on BALB/c mice with or without microneedle array pretreatment using DT as a model antigen co-administrated with lipopolysaccharide (LPS), Quil A, CpG oligo deoxynucleotide $(\mathrm{CpG})$ or cholera toxin $(\mathrm{CT})$ as adjuvant. The immunogenicity was evaluated by measuring serum $\operatorname{IgG}$ subtype titers and neutralizing antibody titers.

Results. TCI with microneedle array pretreatment resulted in a 1,000-fold increase of DT-specific serum IgG levels as compared to TCI. The immune response was further improved by co-administration of adjuvants, showing a progressive increase in serum IgG titers when adjuvanted with LPS, Quil A, CpG and CT. IgG titers of the CT-adjuvanted group reached levels comparable to those obtained after DTalum subcutaneous injection. The $\operatorname{IgG} 1 / \mathrm{IgG} 2$ a ratio of DT-specific antibodies decreased in the following sequence: plain DT, Quil A, CT and $\mathrm{CpG}$, suggesting that the immune response was skewed towards the Th1 direction.

Conclusions. The potency and the quality of the immune response against DT administered by microneedle array mediated TCI can be modulated by co-administration of adjuvants.

KEY WORDS: cholera toxin; $\mathrm{CpG}$; diphtheria toxoid; microneedle array; transcutaneous immunization.

\section{INTRODUCTION}

Currently, most vaccines are administrated by injection. Costs, risks and discomforts associated with the use and abuse of needles have boosted research on needle-free vaccinations (1). Around 10 years ago, Glenn, G.M et al. reported for the first time data on transcutaneous immunization (TCI) and showed that strong immune responses could be induced by topically applied cholera toxin (2). TCI is particularly attractive because of the high accessibility of the skin and the presence of antigen-presenting cells (APCs) in the epidermis and dermis, in particular the Langerhans cells

\footnotetext{
${ }^{1}$ Division of Drug Delivery Technology, Leiden/Amsterdam Center for Drug Research (LACDR), Leiden University, Einsteinweg 55, 2333 CC, Leiden, The Netherlands.

${ }^{2}$ Department of Research and Development, Netherlands Vaccine Institute, 3720 BA, Bilthoven, The Netherlands.

${ }^{3}$ State Key Laboratory of Pharmaceutical Biotechnology, Biochemistry Department, Nanjing University, 210093, Nanjing, People's Republic of China.

${ }^{4}$ To whom correspondence should be addressed. (e-mail: bouwstra@ lacdr.leidenuniv.nl)

ABBREVIATIONS: Alum, Adju-Phos ${ }$, colloidal aluminum phosphate; CM199, complete medium 199; CRM 197, cross-reacting material of diphtheria toxin; CT, cholera toxin; DT, diphtheria toxoid; HRP-GAM IgG, horseradish peroxidase conjugated goat anti-mouse IgG; M-TCI, TCI with microneedle array pretreatment; TCI, transcutaneous immunization.
}

(LCs) and the dermal dendritic cells (DCs) (3). However, the upper layer of the skin, the stratum corneum, acts as a barrier for diffusion of macromolecules and therefore is a major obstacle to dermal vaccine delivery. To overcome this barrier and achieve effective TCI, physical methods such as intradermal injection (4,5), thermal ablation (6), microdermabrasion (7) electroporation (8) and cavitational ultrasound (9) have been used. Physical disruption of the skin barrier increases the percutanous penetration of the antigen and makes the antigen more readily available for sampling by APCs (10). Moreover, disruption of the skin barrier may induce a chain of molecular events that lead to the secretion of pro-inflammatory cytokines and facilitate APC activation.

A relatively novel approach to disrupt the skin barrier in a controlled manner with little pain sensation is the use of microneedle arrays. It was proposed first by Gerstel and Place already in the 1970s (11). Ten years ago, when the technology for fabrication in micron dimensions became readily available, Prausnitz resumed the study using microneedle arrays in transdermal drug delivery (12). When used as a pretreatment, microneedle arrays enable antigens to diffuse along the transiently formed tiny conduits through the stratum corneum. Thereby antigens may be able to approach the LCs in the epidermis and the DCs in the dermis (13). Using ovalbumincoated microneedle array, Matriano et al. evaluated the uniformity of skin piercing, and studied the dose of the vaccine used and the kinetics and magnitude of antibody titers induced in hairless guinea pigs (14). Widera et al. investigated the 
influence of important fabrication parameters, e.g. length and density of the microneedles, area and coating of the microneedle arrays, on vaccination efficiency of TCI (15). Hooper et al. reported that smallpox DNA vaccine-coated microneedle arrays applied topically in combination with electroporation protected mice against lethal challenge (16). Recently, Van Damme et al. tested the injectable microneedle array in human volunteers using influenza vaccine, resulting in a comparable seroprotection rate as compared to i.m. injection with 5 fold dose sparing (17). These interesting results show that TCI using microneedle array is promising. However, after more than 10 years of extensive research $(18,19)$, there continues to be a need for further improvement of microneedle array mediated TCI, e.g. by using potent adjuvants or novel ways of applying the microneedle arrays.

Recently a new electric applicator was developed in our lab. It is designed to insert microneedle arrays into the skin with a predetermined velocity and thereby counteracts the elasticity of the skin. This applicator enables us to reproducibly pierce human and mouse skin in vivo with microneedles with a length of $300 \mu \mathrm{m}$ or less (20). DT was recruited as a model antigen to evaluate the potential of microneedle array pretreatment in TCI. In a previous study the immunogenicity of topically applied DT was dramatically improved by microneedle array pretreatment as compared to untreated skin (21).

The objective of the present study was to determine the effect of adjuvants on the quantity and quality of the immune response against DT after TCI with microneedle array pretreatment (M-TCI). The Th1/Th2 balance of the immune response depends on several factors including the nature of the antigen and the adjuvant, the delivery route and the targeted APCs, as suggested by the ratio of IgG1/IgG2a antibody titers (22). The adjuvants included in this study, cholera toxin (CT), lipopolysaccharide (LPS), synthetic oligo deoxynucleotide containing a CpG motif ( $\mathrm{CpG})$, immunostimulatory fractions extracted from the bark of the tree Quillaja saponica (Quil A) and aluminum phosphate (alum), differ in their adjuvant mechanism and ability to modulate the immune response (see Table I) (22). Immune modulation by these adjuvants was evaluated in (M-)TCI and compared with conventional subcutaneous (s.c.) injection of DT or DT-alum, by measuring serum IgG (subtype) titers and neutralizing antibody titers.

\section{MATERIALS AND METHODS}

\section{Materials}

Diphtheria toxin (batch 79/1), diphtheria toxoid (batch 98/40, protein content $12.6 \mathrm{mg} / \mathrm{ml}$ by BCA assay, $1 \mu \mathrm{g}$ equal to approximately $0.3 \mathrm{Lf}$ ) and the IpxL1 LPS were provided by the Netherlands Vaccine Institute (NVI, Bilthoven, The Netherlands). Horseradish peroxidase-conjugated goat antimouse (HRP-GAM) IgG ( $\gamma$-chain specific), IgG1 ( $\gamma 1$-chain specific) and IgG2a ( $\gamma 2 \mathrm{a}$-chain specific) were purchased from Southern Biotech (Birmingham, USA). Quil A and AdjuPhos ${ }^{\circledR}$ (alum) were obtained from Brenntag Biosector (Copenhagen, Denmark). CpG oligo deoxynucleotide 1826 (5'-tcc atg acg ttc ctg acg tt-3', phosphorothioated) was synthesized by Isogen Biosolutions (IJsselstein, The Netherlands). Chromogen 3, 3', 5, 5'-tetramethylbenzidine (TMB) and the substrate buffer were purchased from Biosource B.V. (Nivelles, Belgium). Cholera toxin was ordered from SigmaAldrich (Zwijndrecht, The Netherlands). Nimatek $\AA$ (100 mg/ ml Ketamine, Euovet Animal Health B.V., Bladel, The Netherlands), Rompun ${ }^{\circledR}$ (20 mg/ml Xylasine, Bayer B.V., Mijdrecht, The Netherlands) and the injection fluid $(0.9 \%$ $\mathrm{NaCl}$ ) were obtained from a local pharmacy. All other chemicals used were of analytical grade and all solutions were prepared with distilled water.

\section{Animals}

Female BALB/c mice (H2d), 8-week old at the start of the experiment were purchased from Charles River (Maastricht, The Netherlands), and maintained under standardized conditions in the animal facility of the Leiden/Amsterdam Center for Drug Research, Leiden University. The study was conducted in conformity with the Public Health Service Policy on use of laboratory animals and had been approved by the Research Ethical Committee of Leiden University (UDEC, nr. 07016).

\section{Methods}

\section{Microneedle Array and Applicator}

Assembled microneedle arrays were manufactured from commercially available $30 \mathrm{G}$ hypodermic needles (BD, Alphen a/d Rijn, The Netherlands) as described previously (13). The needles were assembled as a $300 \mu \mathrm{m}$-long, $4 \times 4$ array on a polymer back plate with a surface area of about $0.5 \mathrm{~cm}^{2}$. The electric applicator was developed and optimized as reported previously (21). The microneedles were pierced into mouse skin using a velocity of $3 \mathrm{~m} / \mathrm{s}$.

\section{Immunization Study}

The DT-alum formulations were prepared as previously described and the adsorption of DT to alum was between

Table I. Properties of the Adjuvants Employed in the Current Study (Adapted from $(22,47,48)$ )

\begin{tabular}{llccl}
\hline \multicolumn{1}{c}{ Adjuvant } & \multicolumn{1}{c}{ Type } & Cell-mediated immunity (Th1) & Humoral immunity (Th2) & Receptor \\
\hline Cholera toxin & Exotoxin & $+^{a}$ & +++ & GM1 ganglioside \\
$l p x$ 1 LPS & Endotoxin & ++ & ++ & TLR4 \\
Quil A & Saponin based & +++ & ++ & Not identified \\
CpG & Bacterial DNA & ++++ & + & TLR9 \\
Alum & Inorganic salt & + & +++ & Not identified \\
\hline
\end{tabular}

\footnotetext{
${ }^{a}$ Humoral and cellular immunity in arbitrary units represent the ability of adjuvants to enhance Th2 response or CTL or Th1, respectively, to
} foreign antigens 
$70 \%$ and $80 \%$ (23). As control groups, $5 \mu \mathrm{g}$ of DT ( $\sim 1.5 \mathrm{Lf})$ with and without alum in $100 \mu \mathrm{l}$ solution/suspension was administered per mouse by s.c injection. The other vaccineadjuvant formulations were freshly prepared by mixing DT and the adjuvants in buffer solution in appropriate amounts as indicated in Table II. One hundred micrograms DT and adjuvants per mouse were applied on intact skin (TCI) or on microneedle array pretreated skin (M-TCI) as previously described (21,24). A mutant of LPS, lpxL1 LPS, with reduced toxicity but retained adjuvanticity, was employed in this study (25). The dose of alum and lpxL1 LPS used in M-TCI were based on the $w / w$ ratio of antigen/adjuvant used in injection control group and previous immunization study (25), respectively.

During vaccination, mice were anaesthetized by intraperitoneal injection of $150 \mathrm{mg} / \mathrm{kg}$ ketamine and $10 \mathrm{mg} / \mathrm{kg}$ xylazine. For all groups receiving transcutaneous vaccination, the abdominal skin of the mice, shaved $24 \mathrm{~h}$ prior to vaccination, was first wiped with $70 \%$ ethanol. For M-TCI group, a skin fold was supported by styrofoam and pierced using the microneedle array and the electric applicator. Then $70 \mu \mathrm{l}$ DT-adjuvant formulation was carefully spread to wet the entire skin area of application (microneedle array-pretreated or untreated, $\sim 2 \mathrm{~cm}^{2}$ area restricted by a metal ring). After $1 \mathrm{~h}$ of occlusive incubation, the skin area was extensively washed with lukewarm tap water and patted dry twice. All mice were immunized three times on day 1, 21 and 42 (at approximately the same skin region for all the TCI groups) and sacrificed on day 56. Blood was sampled from the tail vein one day before each immunization and the whole blood was collected from the femoral artery during sacrifice. Cell free sera were obtained using MiniCollect ${ }^{\circledR}$ tubes (Greiner bio-one, Alphen a/d Rijn, The Netherlands) by centrifugation after clot formation and stored at $-80^{\circ} \mathrm{C}$.

\section{Serum Antibody Assay}

Serum $\mathrm{IgG}, \mathrm{IgG} 1$ and $\mathrm{IgG} 2 \mathrm{a}$ titers were determined by sandwich ELISA as previously described (26). Briefly, ELISA plate (Microlon ${ }^{\circledR}$, Greiner Bio-one, Alphen a/d Rijn, The Netherlands) wells were coated with DT at $4^{\circ} \mathrm{C}$ overnight. Two-fold serial dilutions of serum samples were applied in the plates and the containing DT-specific antibodies were detected by HRP-GAM IgG, IgG1 or IgG2a using TMB as substrate. Antibody titers are expressed as the reciprocal of the calculated sample dilution corresponding to half of the maximum absorbance at $450 \mathrm{~nm}$ of a complete sshaped absorbance-log dilution curve. If samples were not diluted in the optimal range, additional measurements were performed to generate an s-shaped curve. Subsequently, the titers were calculated using a four-parameter fitting of the curve. Samples that did not reach the half-saturated absorbance value at the lowest (ten fold) dilution were considered as non-responders.

\section{Neutralizing Antibody Assay}

Immunity against diphtheria depends on the presence of circulating toxin-neutralizing antibodies. These antibodies were evaluated using Vero cell test, the WHO standard method to assess the success of diphtheria vaccination, which relies on the inhibition of a cytotoxic dose of diphtheria toxin (26). In brief, after complement inactivation, two-fold serial dilutions of serum samples were prepared with complete medium 199 (CM199, Gibco, Breda, The Netherlands) and applied to microtiter plates (CELLSTAR®, Greiner Bio-one, Alphen a/d Rijn, The Netherlands). Subsequently, $2.5 \times 10^{-5} \mathrm{Lf}$ diphtheria toxin was added to the wells. After $2 \mathrm{~h}$ incubation at $37^{\circ} \mathrm{C}$ for neutralization, Vero cells suspension in CM199 was added to each well. Covered with a plate sealer, Vero cells were incubated at $37^{\circ} \mathrm{C}$ in $5 \% \mathrm{CO}_{2}$ for 6 days. The end point was taken as the highest serum dilution protecting the Vero cells.

\section{Statistical Analysis}

ELISA titers were logarithmically transformed for better normality before statistical analysis. Two way ANOVA with Bonferroni posttest, one way ANOVA with Tukey posttest, or Kruskal-Wallis nonparametric test with Dunns posttest were performed as indicated. Statistical analysis was carried out using Prism Graphpad and a $p$ value less than 0.05 was considered to be significant.

\section{RESULTS}

During the immunization study, there was no adverse effect from the shaving, anesthesia, piercing, immunization, or washing procedure observed. Neither erythema nor indura-

Table II. Formulations Prepared for In Vivo (M-)TCI Study

\begin{tabular}{|c|c|c|c|c|}
\hline DT dose $(\mu \mathrm{g})$ & Adjuvants & Adjuvant dose $(\mu \mathrm{g})$ & Solvent (pH) & Volume $(\mu \mathrm{l})$ \\
\hline \multicolumn{5}{|c|}{ for s.c. injection } \\
\hline 5 & $\mathrm{AlPO}_{4}$ & 150 & $0.9 \%$ saline $(7.0)$ & 100 \\
\hline 5 & - & - & $0.9 \%$ saline $(7.0)$ & 100 \\
\hline \multicolumn{5}{|l|}{$(M)-T C I$} \\
\hline 100 & - & - & $\operatorname{PBS}^{a}(7.4)$ & 70 \\
\hline 100 & lpxL1 LPS & 25 & PBS/Tris ${ }^{b}$ (7.4) & 70 \\
\hline 100 & Quil A & 100 & PBS (7.4) & 70 \\
\hline 100 & CT & 100 & PBS (7.4) & 70 \\
\hline 100 & $\mathrm{CpG}$ & 100 & PBS (7.4) & 70 \\
\hline 100 & $\mathrm{AlPO}_{4}$ & 3,000 & $0.9 \%$ saline $(7.0)$ & 70 \\
\hline
\end{tabular}

${ }^{a}$ PBS: $2.67 \mathrm{mM} \mathrm{KCl}, 1.47 \mathrm{mM} \mathrm{KH} \mathrm{PO}_{4}, 137.93 \mathrm{mM} \mathrm{NaCl}, 8.06 \mathrm{mM} \mathrm{Na}_{2} \mathrm{HPO}_{4} \cdot 7 \mathrm{H}_{2} \mathrm{O}$, without $\mathrm{Ca}^{2}{ }^{+}$and $\mathrm{Mg}^{2+}$

${ }^{b}$ PBS/Tris: PBS mixed with $1 \mathrm{mM}$ Tris- $\mathrm{HCl}(v / v=5: 3)$. 
tion was seen at the immunization site after exposure of antigen and adjuvants.

\section{Immune Response Improved by Microneedle Array Pretreatment}

The IgG titers of mice from all groups after prime, first boost and second boost (day 20,41 and 56) are shown in Fig. 1a-e and an overview of the DT-IgG titers after the second boost is shown in Fig. 1f. It is clear that nonadjuvanted DT did not result in a substantial IgG response when applied on intact skin (TCI). Microneedle array pretreatment provided major improvement to the immunogenicity of DT. After prime, more mice responded with higher mean $\mathrm{IgG}$ titers in the M-TCI group than in the TCI group. After the first boost, all mice responded and the $\mathrm{IgG}$ titers were 100 fold higher in the M-TCI group $(p<0.01)$ and the difference of $\mathrm{IgG}$ titers was further increased to over 1,000 fold after the second boost $(p<0.001$, Fig. 1a). Immunogenicity of DT was further improved by the co-administered adjuvants e.g. Quil A, $\mathrm{CpG}$ and $\mathrm{CT}$ in M-TCI. The improvement by the adjuvant in question is indicated by the space in between the black and the brown lines in Fig. 1b, c, d and e, respectively. DT-specific IgG titers in the CT M-TCI group after the second boost were the highest among all M-TCI groups and reached very close level to those from DT-alum injection group $(p>0.05)$. For the adjuvants in the absence of microneedle array pretreatment, their effects on the DT immunogenicity were more variable and less pronounced. Only CT moderately improved the IgG titers after the second boost (Fig. 1a, e, $p<0.05$ ), while the presence of the other adjuvants did not augment the $\mathrm{IgG}$ titers significantly. Comparing the two injection control groups, alum speeded up $\mathrm{IgG}$ development and increased the IgG titers significantly $(p<0.001$ after first boost).
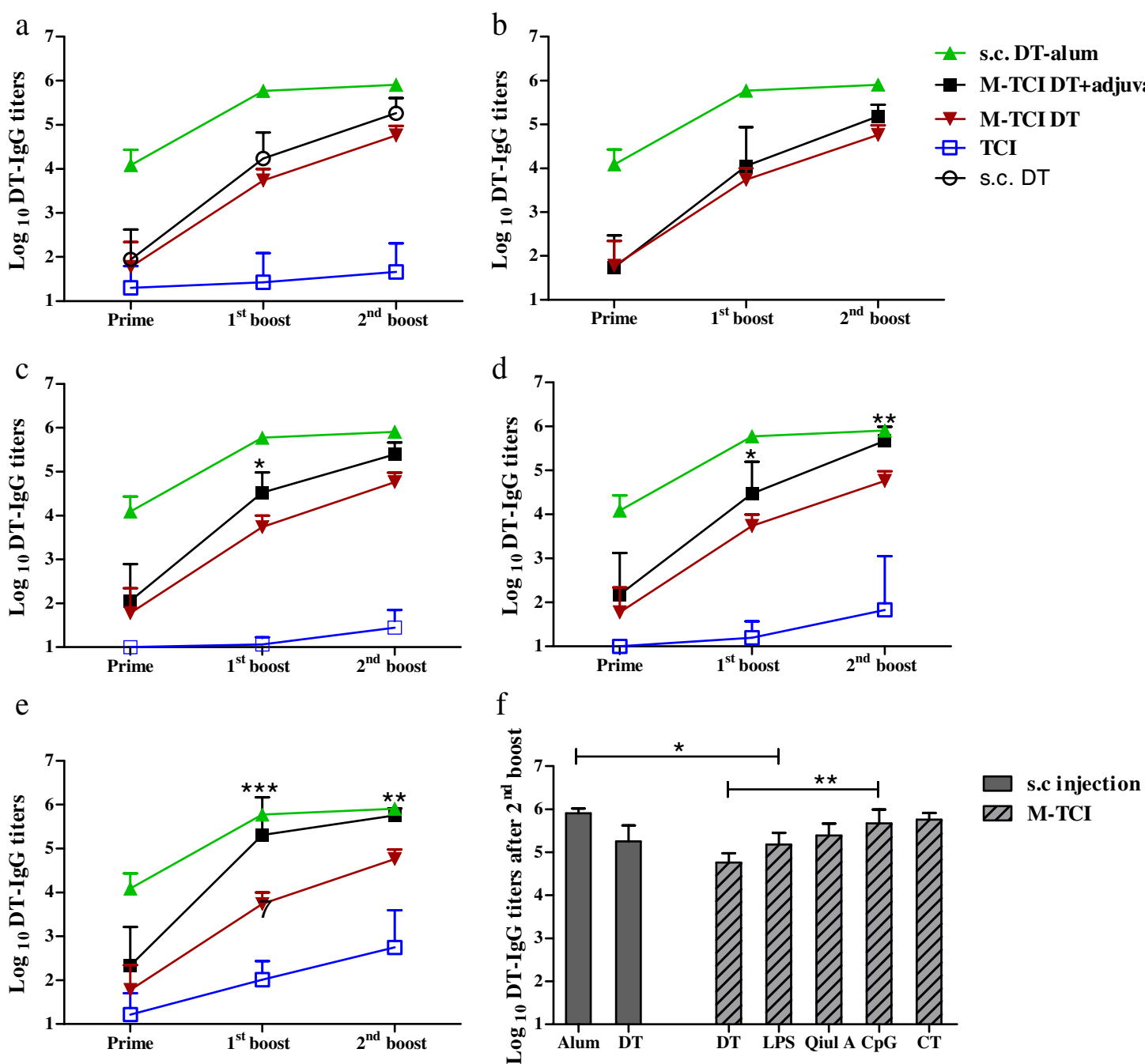

Fig. 1. DT-specific IgG titers to dermally delivered DT with (M-TCI) and without (TCI) microneedle array pretreatment of the skin: a Plain DT; b DT + LPS; c DT + Quil A; d DT + CpG; e DT + CT. Sera were collected after prime, first boost and second boost (day 20, 41 and 56) and antibodies were determined by ELISA. TCI with DT + LPS was not carried out. An overview of the DT-specific IgG titers after the second boost for the M-TCI and s.c. injection groups are shown in $\mathbf{f}$. Data are shown as mean $+\mathrm{SD}(n=8)$. Non-responders were given an arbitrary titer of $10\left({ }^{*} p<0.05, * * p<0.01, * * * p<0.001\right.$, two way ANOVA with Bonferroni posttest). 
However, when DT-alum was applied in M-TCI, no adjuvanticity was observed as the $\mathrm{IgG}$ titers were lower than those of plain DT in M-TCI (data not shown).

\section{Immune Modulation by Adjuvants in M-TCI}

Focusing on the M-TCI, immune modulation functions of the adjuvants were investigated. The DT-specific IgG1 and IgG2a titers in the sera collected after prime, first boost and second boost (day 21, 42 and 56) were determined (Fig. 2). For all adjuvants, IgG1 showed similar titers as compared to the total IgG titers and each vaccination showed a booster effect. After the first boost, Quil A and CT enhanced the IgG1 titers significantly as compared to plain DT $(p<0.01$ and 0.001 , respectively). After the second boost, only CT significantly enhanced the IgG1 titers as compared to plain DT $(p<$ $0.01)$. A clear effect of the adjuvants on the IgG2a titers was observed after the second boost, which increased in the following sequence: plain DT, LPS, Quil A, CT and CpG.

The IgG1/IgG2a ratio, which is considered a measure for the Th1/Th2 balance of the immune response (27), of individual mice from each group after the second boost was calculated and presented in Fig. 3. Plain DT and DT-alum induced an IgG1 biased response when delivered via s.c. injection. Applying plain DT by M-TCI induced the same
$\mathrm{IgG} 1 / \mathrm{IgG} 2 \mathrm{a}$ ratio as by s.c. injection. With adjuvants, the ratio decreased in the following sequence: plain DT, Quil A, CT and $\mathrm{CpG}$, suggesting that the $\mathrm{Th} 2$ biased immune response induced by plain DT was skewed towards the Th1 direction.

\section{Protective Immunity of DT in M-TCI}

The protective immunity of DT with the serial of immune modulators in M-TCI was evaluated using the Vero cells test (Fig. 4). Although for LPS, Quil A and CpG groups the neutralizing antibody titers were not significantly different from those for plain DT, improvement was seen for the CT group $(p<0.05)$. The mean titer was very close to that of the DT-alum injection group, and the difference was not significant $(p>0.05)$. As expected, the groups that had received formulations on untreated skin (TCI) did not show detectable neutralizing antibody titers.

\section{DISCUSSION}

This is the first study in which the immune modulatory activity of several known adjuvants was directly compared in TCI with microneedle array pretreatment, using DT as a model antigen. In this study, we first compared the immune responses of DT formulated with different adjuvants in TCI
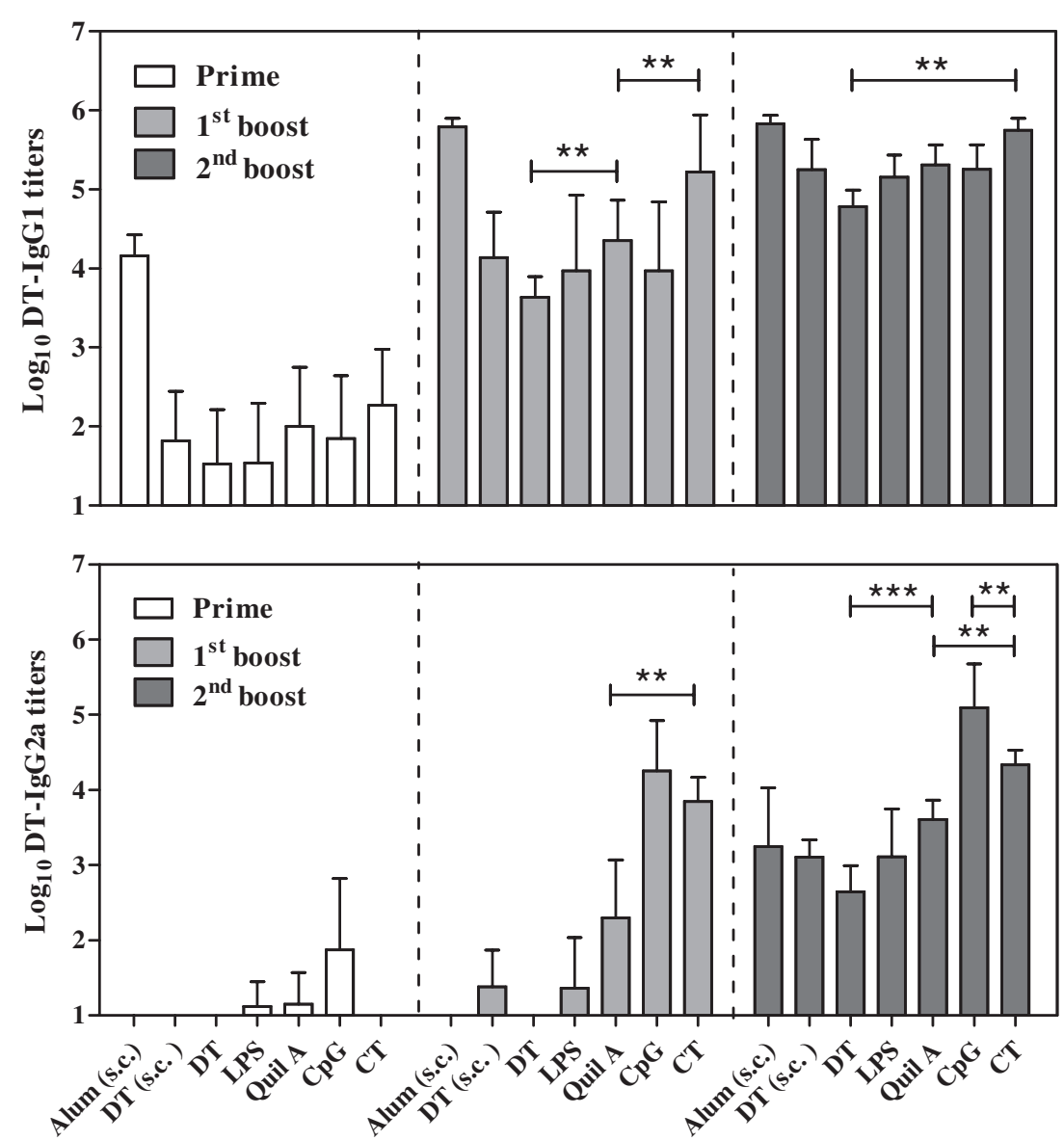

Fig. 2. DT-specific IgG1 and IgG2a titers during M-TCI. Sera were collected after prime, first boost and second boost (day 20,41 and 56) and antibodies were determined by ELISA. Data shown as mean $+\mathrm{SD}(n=8)$. Non-responders were given an arbitrary titer of 10. $\left({ }^{*} p<0.05,{ }^{* *} p<0.01,{ }^{* * *} p<0.001\right.$, two way ANOVA with Bonferroni posttest). 


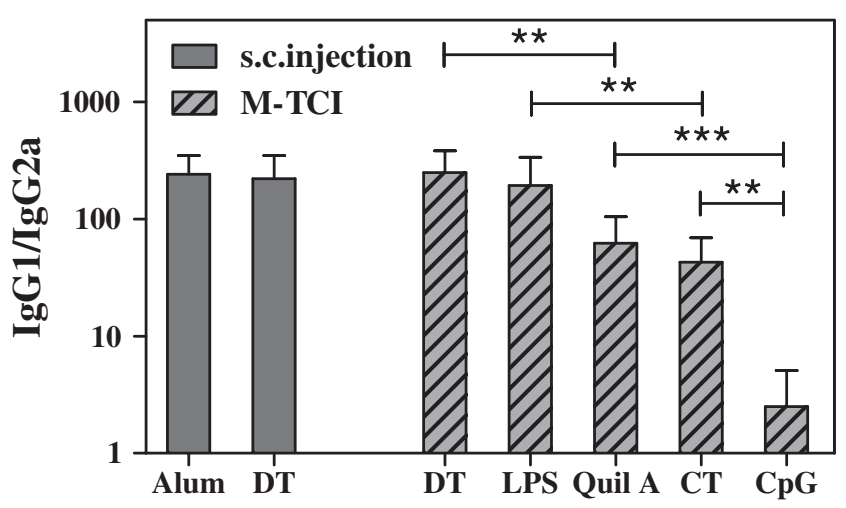

Fig. 3. DT-specific $\operatorname{IgG} 1 / \operatorname{IgG} 2$ a ratios of individual mouse after $\mathrm{M}$ TCI. Sera were collected on day 56, DT-specific IgG1 and IgG2a titers were measured by sandwich ELISA. IgG1/IgG2a ratios were calculated only using IgG2a responders. Data shown as mean $+\mathrm{SD}$ $(n=8, * * p<0.01$ and $* * * p<0.001$, one-way ANOVA with Tukey posttest).

and M-TCI. Then we focused our study on the modulation capability of these adjuvants to the immune response in M-TCI.

Application of DT on intact skin did not induce a substantial immune response in the absence or presence of the tested adjuvants. The poor penetration of DT across the stratum corneum seems to be the limiting factor, since the antibody titers of DT in TCI was strongly increased by microneedle array pretreatment. The skin barrier disruption and increased DT diffusion across the stratum corneum provided remarkable improvement to the immune response via TCI, similar as the tape-stripping method, however, through a practically easier and more controllable approach (28). Co-administration of adjuvants in M-TCI was able to further augment the immunogenicity of DT and demonstrated marked differences between the immune stimulatory activities of the adjuvants. In the following section, the tested adjuvants are discussed individually concerning their mechanism of action and the role of delivery route in the augmentation and modulation of DT immune response.

$\mathrm{CT}$ is a molecule with five nontoxic B subunits (CTB) surrounding a single, toxic A fragment (CTA). Both the CTBmediated specific binding to the GM1 ganglioside receptors and the ADP-ribosyltransferase activity of CTA have been reported to be of importance for the immune stimulatory properties of CT $(29,30)$. Whereas CT is a well-documented Th2 immune modulator in conventional and mucosal vaccination (30), our results point to a more Th1 biased response against DT when co-administered with $\mathrm{CT}$ via M-TCI. The Th1 skewing of CT in TCI was also reported by Stickings et al. using mutant diphtheria toxin, CRM197, as model antigen (31) and by Skountzou et al. using influenza vaccine (32). This suggests that the Th1 skewing of CT is delivery-route dependent. Studies performed by Anjuere et al. using ovalbumin as prototype antigen clarified that CTB suppresses systemic Th1 responses when given by a mucosal route, but potentiates these responses when administered by TCI. This finding underscores the role of the epithelial microenvironment in the regulation of immune responses and reflects the DC heterogeneity between mucosal tissue and skin (33).
The signaling of $\mathrm{CpG}$ starts by engagement of Toll-like receptor 9 (TLR9), followed by induction of pro-inflammatory cytokine (e.g. IL-12, TNF- $\alpha$ and IFN- $\gamma$ ) expression, and results in a Th1 biased response (34). In our present study, CpG induced the highest IgG2a titers among all M-TCI groups and our results strongly support a skewing of the Th1/Th2 balance towards the Th1 direction, similar to the immune modulatory effect of $\mathrm{CpG}$ in mucosal and injection vaccination. Although at the site of application TLR9 is not constitutively expressed by the LCs, it is almost exclusively expressed by the keratinocytes in the upper and most differentiated layer of the epidermis. Their TLR9 expression and reactivity to CpG is reported to be greatly up-regulated by transforming growth factor (TGF- $\alpha$ ), a growth and differentiation factor present after skin barrier disruption and during wound healing (35).

Quil A is composed of immune-stimulatory fractions extracted from the bark of the tree Quillaja saponica. The Quil A concentration $(1.43 \mathrm{mg} / \mathrm{ml})$ used in the applied formulation was well above its reported critical micelle

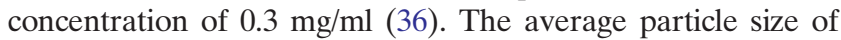
the DT-Quil A dispersion in PBS was about $56 \mathrm{~nm}$ with a PDI of 0.10 , as measured by dynamic light scattering. Quil A is a potent Th1 biased adjuvant when given by i.m. injection (37). In M-TCI, it improved the IgG titers marginally as compared to the non-adjuvanted DT ( $p<0.05$ after the first boost; $p>0.05$ after the second boost). The ratios of anti-DT IgG1/IgG2a titers were significantly lowered as compared to M-TCI of plain DT $(p<0.01)$, suggesting that it skewed the response towards the Th1 direction.

LPS, major outer membrane constituent of Gramnegative bacteria, stimulates APCs through TLR4, induces high levels of pro-inflammatory cytokines and usually leads to a strong Th1 response (38). The DT-lpxL1 LPS dispersion applied in our study had a bigger average particle size than Quil A, about $300 \mathrm{~nm}$ with a PDI of 0.45 , indicating that relatively large complexes had been formed. In M-TCI, the effect of the lpxL1 LPS mutant on the anti-DT IgG, $\operatorname{IgG} 1, \operatorname{IgG} 2 \mathrm{a}$ and the neutralizing antibody titers was not significant $(p>0.05)$. This may be due to the following factors: (a) LCs do not express TLR4 and do not respond to

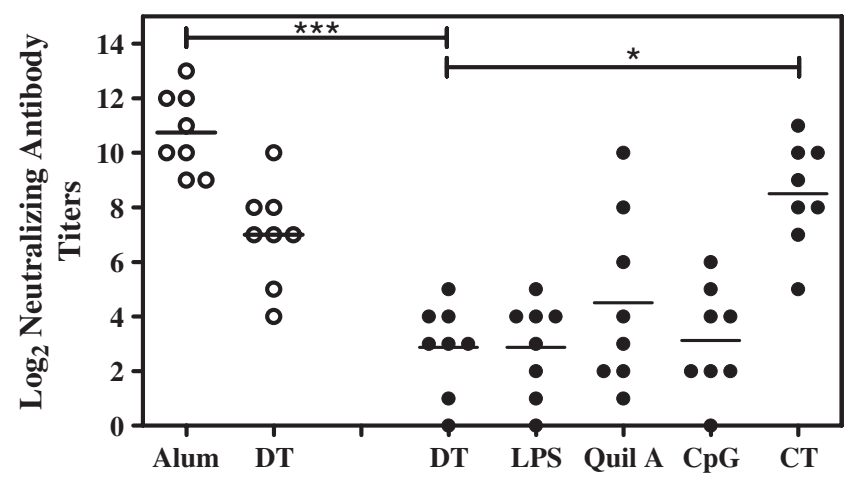

Fig. 4. Diphtheria toxin-neutralizing antibody titers after M-TCI. Serum samples were collected after the second boost (day 56) and determined by Vero cell test. Data are expressed as logarithm of the highest dilution that was still capable of protecting the Vero cells from the challenge of diphtheria toxin (filled circle the M-TCI groups, empty circle the injection groups, ${ }^{*} p<0.05,{ }^{*} p<0.01$, $* * * p<0.001$, Kruskal-Wallis nonparametric test with Dunns posttest). 
bacteria or LPS (39). TLR4 expression by mouse keratinocytes also seems limited. Besides few data available from mice, reports on TLR4 expression by human keratinocytes are conflicting (40,41); (b) Although little is known about the actual diffusion of these dispersions across the conduits induced by the microneedles, previous studies of our group showed that fluorescently labeled particles of ca. $200 \mathrm{~nm}$ did pass through the conduits created by the same microneedle arrays as used in the present study (20). However, as no quantitative information is available, it is possible that only a limited amount of the DTlpxL1 LPS dispersion reached the DCs in the dermis; (c) the LPS mutant may work in a less efficient way as the original LPS in the epidermal/dermal microenvironment. Further studies are required to elucidate the exact mechanism. The different reactivity of skin immune system to $\mathrm{CpG}$ and LPS may be involved in a strategic control of host defense to the bacterial commensal skin flora (39).

Alum did not show any adjuvanticity in M-TCI. It induced lower IgG and IgG1 titers than those of non-adjuvanted DT group after each vaccination. Furthermore, alum in M-TCI did not induce detectable $\mathrm{IgG} 2 \mathrm{a}$ titers and provided no protection in the Vero cell test after the second boost (data not shown). This may partially be due to the size of DT-alum particles, several microns in diameter, which prevents their diffusion through the conduits in sufficient amount to exert a 'depot' effect (42). The adjuvanticity of alum could also be dependent on the epithelial microenvironment; the danger signal it induces through injection, the uric acid production (43), may not be provoked in the dermis and epidermis.

Interestingly, when comparing IgG subtype titers and neutralizing antibody titers between $\mathrm{CpG}$ and Quil A groups (Figs. 1 and 4), the $\mathrm{CpG}$ group, with similar IgG titers, but much higher $\operatorname{IgG} 2$ a titers than the other, induced similar to slightly lower neutralizing antibody titers, which indicates that IgG2a might not contribute to toxin-neutralization. This was confirmed by the comparison between $\mathrm{CpG}$ and CT groups, also showing that higher IgG2a titers did not result in higher neutralizing antibody titers. IgG1 seems to be the main neutralizing antibody for protection, as IgG1 titers significantly correlated with neutralizing titers. However, IgG1 titers could not be used to predict individual neutralizing antibody titers with great accuracy, which is in line with a diphtheria vaccination study done in human infants (44). Therefore, from an application perspective, $\mathrm{CpG}$ in M-TCI is more suitable for anti-viral immune responses such as influenza vaccination where IgG2a provides the main immune protection and a Th1 biased response is more desired (45).

In this study, a high dose of DT, 20 times of that used in the s.c. injection group, was applied in M-TCI. This dose is similar to the dose of DT used by Glenn et al. in previous studies $(24,46)$. High doses were used as apparently only a fraction of DT applied actually enters epidermis/dermis. A limiting factor for diffusion of the antigen into the skin is that the mice used for this study can only be kept under anesthesia for about $1 \mathrm{~h}$. This is not a limitation of the transcutaneous route, but a limitation of the animal model used. The high doses used until now also indicate that formulation improvement to increase the efficiency of the immune response is very important in transcutaneous vaccination. Conjugation and encapsulation of adjuvants into vaccine-containing par- ticles and specific DC and LC targeting approaches could be attractive strategies to further improve the potency of vaccine formulations for M-TCI.

\section{CONCLUSION}

We have shown that the type of adjuvant used has a significant effect on the immune response and protective immunity against DT in M-TCI. The epithelial microenvironment and DC heterogeneity also play an important role in the regulation of the immune response. This delivery method is applicable to many other vaccines by formulating with proper adjuvants and holds a lot of promise for future use.

\section{ACKNOWLEDGEMENTS}

Henk Verpoorten from the Fine Mechanic Department (FMD) of Leiden University is acknowledged for manufacturing the assembled microneedle arrays. Dr. Rob J. Vandebriel from the National Institute of Public Health and the Environment (RIVM) of the Netherlands is acknowledged for helpful discussions. This work was financially supported, in part, by the Chinese Scholarship Council (CSC).

Open Access This article is distributed under the terms of the Creative Commons Attribution Noncommercial License which permits any noncommercial use, distribution, and reproduction in any medium, provided the original author(s) and source are credited.

\section{REFERENCES}

1. Giudice EL, Campbell JD. Needle-free vaccine delivery. Adv Drug Deliv Rev 2006;58:68-89. doi:10.1016/j.addr.2005.12.003.

2. Glenn GM, Rao M, Matyas GR, Alving CR. Skin immunization made possible by cholera toxin. Nature 1998;391:851. doi:10.1038/36014.

3. Kupper TS, Fuhlbrigge RC. Immune surveillance in the skin: mechanisms and clinical consequences. Nat Rev Immunol 2004;4:211-22. doi:10.1038/nri1310.

4. Alarcon JB, Hartley AW, Harvey NG, Mikszta JA. Preclinical evaluation of microneedle technology for intradermal delivery of influenza vaccines. Clin Vaccine Immunol 2007;14:375-81. doi:10.1128/CVI.00387-06.

5. Mikszta JA, Dekker JP 3rd, Harvey NG, Dean CH, Brittingham JM, Huang J, Sullivan VJ, Dyas B, Roy CJ, Ulrich RG. Microneedle-based intradermal delivery of the anthrax recombinant protective antigen vaccine. Infect Immun 2006;74:680610. doi:10.1128/IAI.01210-06.

6. Garg S, Hoelscher M, Belser JA, Wang C, Jayashankar L, Guo Z, Durland RH, Katz JM, Sambhara S. Needle-free skin patch delivery of a vaccine for a potentially pandemic influenza virus provides protection against lethal challenge in mice. Clin Vaccine Immunol 2007;14:926-8. doi:10.1128/CVI.00450-06.

7. Glenn GM, Flyer DC, Ellingsworth LR, Frech SA, Frerichs DM, Seid RC, Yu J. Transcutaneous immunization with heat-labile enterotoxin: development of a needle-free vaccine patch. Expert Rev Vaccines 2007;6:809-19. doi:10.1586/14760584.6.5.809.

8. Zhao YL, Murthy SN, Manjili MH, Guan LJ, Sen A, Hui SW. Induction of cytotoxic T-lymphocytes by electroporationenhanced needle-free skin immunization. Vaccine 2006;24:1282-90. doi:10.1016/j.vaccine.2005.09.035.

9. Ogura M, Paliwal S, Mitragotri S. Low-frequency sonophoresis: current status and future prospects. Adv Drug Deliv Rev 2008;60:1218-23. doi:10.1016/j.addr.2008.03.006. 
10. Partidos CD, Muller S. Decision-making at the surface of the intact or barrier disrupted skin: potential applications for vaccination or therapy. Cell Mol Life Sci 2005;62:1418-24. doi:10.1007/s00018-005-4529-1.

11. Gerstel MS, Place VA. Drug delivery device, US, 1976.

12. Henry S, McAllister DV, Allen MG, Prausnitz MR. Microfabricated microneedles: a novel approach to transdermal drug delivery. J Pharm Sci 1999;88:948.

13. Verbaan FJ, Bal SM, van den Berg DJ, Groenink WH, Verpoorten H, Luttge R, Bouwstra JA. Assembled microneedle arrays enhance the transport of compounds varying over a large range of molecular weight across human dermatomed skin. J Control Release 2007;117:238-45. doi:10.1016/j.jconrel.2006.11.009.

14. Matriano JA, Cormier M, Johnson J, Young WA, Buttery M, Nyam K, Daddona PE. Macroflux microprojection array patch technology: a new and efficient approach for intracutaneous immunization. Pharm Res 2002;19:63-70. doi:10.1023/ A:1013607400040.

15. Widera G, Johnson J, Kim L, Libiran L, Nyam K, Daddona PE, Cormier M. Effect of delivery parameters on immunization to ovalbumin following intracutaneous administration by a coated microneedle array patch system. Vaccine 2006;24:1653-64. doi:10.1016/j.vaccine.2005.09.049.

16. Hooper JW, Golden JW, Ferro AM, King AD. Smallpox DNA vaccine delivered by novel skin electroporation device protects mice against intranasal poxvirus challenge. Vaccine 2007;25: 1814-23. doi:10.1016/j.vaccine.2006.11.017.

17. Van Damme P, Oosterhuis-Kafeja F, Van der Wielen M, Almagor Y, Sharon O, Levin Y. Safety and efficacy of a novel microneedle device for dose sparing intradermal influenza vaccination in healthy adults. Vaccine 2009;27:454-9. doi:10.1016/j.vaccine.2008.10.077.

18. Sivamani RK, Liepmann D, Maibach HI. Microneedles and transdermal applications. Expert Opin Drug Deliv 2007;4:19-25. doi:10.1517/17425247.4.1.19.

19. Davis SP, Landis BJ, Adams ZH, Allen MG, Prausnitz MR. Insertion of microneedles into skin: measurement and prediction of insertion force and needle fracture force. J Biomech 2004;37:1155-63. doi:10.10161/j.jbiomech.2003.12.010.

20. Verbaan FJ, Bal SM, van den Berg DJ, Dijksman JA, van Hecke M, Verpoorten H, van den Berg A, Luttge R, Bouwstra JA. Improved piercing of microneedle arrays in dermatomed human skin by an impact insertion method. J Control Release 2008;128:80-8. doi:10.1016/j.jconrel.2008.02.009.

21. Ding Z, Verbaan FJ, Bivas-Benita M, Bungener L, Huckriede A, van den Berg DJ, Kersten G, Bouwstra JA. Microneedle Arrays for the Transcutaneous Immunization of Diptheria and Influenza in BALB/c Mice. J Control Release (2009) doi:10.1016/j.jconrel. 2009.01.025.

22. McNeela EA, Mills KH. Manipulating the immune system: humoral versus cell-mediated immunity. Adv Drug Deliv Rev 2001;51:43-54. doi:10.1016/S0169-409X(01)00169-7.

23. Metz B, Jiskoot W, Hennink WE, Crommelin DJ, Kersten GF. Physicochemical and immunochemical techniques predict the quality of diphtheria toxoid vaccines. Vaccine 2003;22:156-67. doi:10.1016/j.vaccine.2003.08.003.

24. Scharton-Kersten T, Glenn GM, Vassell R, Yu J, Walwender D, Alving CR. Principles of transcutaneous immunization using cholera toxin as an adjuvant. Vaccine 1999;17(Suppl 2):S37-43. doi:10.1016/S0264-410X(99)00233-9.

25. van der Ley P, Steeghs L, Hamstra HJ, ten Hove J, Zomer B, van Alphen L. Modification of lipid A biosynthesis in Neisseria meningitidis lpxL mutants: influence on lipopolysaccharide structure, toxicity, and adjuvant activity. Infect Immun 2001;69:5981-90. doi:10.1128/IAI.69.10.5981-5990.2001.

26. Amidi M, Pellikaan HC, Hirschberg H, de Boer AH, Crommelin DJ, Hennink WE, Kersten G, Jiskoot W. Diphtheria toxoidcontaining microparticulate powder formulations for pulmonary vaccination: preparation, characterization and evaluation in guinea pigs. Vaccine 2007;25:6818-29. doi:10.1016/j.vaccine. 2007.05.064.
27. Guy B. The perfect mix: recent progress in adjuvant research. Nat Rev Microbiol 2007;5:505-17. doi:10.1038/nrmicro1681.

28. Godefroy S, Peyre M, Garcia N, Muller S, Sesardic D, Partidos CD. Effect of skin barrier disruption on immune responses to topically applied cross-reacting material, CRM(197), of diphtheria toxin. Infect Immun 2005;73:4803-9. doi:10.1128/IAI.73.8. 4803-4809.2005.

29. Agren LC, Ekman L, Lowenadler B, Lycke NY. Genetically engineered nontoxic vaccine adjuvant that combines B cell targeting with immunomodulation by cholera toxin A1 subunit. J Immunol 1997;158:3936-46.

30. Connell TD. Cholera toxin, LT-I, LT-IIa and LT-IIb: the critical role of ganglioside binding in immunomodulation by type I and type II heat-labile enterotoxins. Expert Rev Vaccines 2007;6:821-34. doi:10.1586/14760584.6.5.821.

31. Stickings P, Peyre M, Coombes L, Muller S, Rappuoli R, Del Giudice G, Partidos CD, Sesardic D. Transcutaneous Immunization with Cross-Reacting Material CRM197 of Diphtheria Toxin Boosts Functional Antibody Levels in Mice Primed Parenterally with Adsorbed Diphtheria Toxoid Vaccine. Infect Immun 2008;76:1766-73. doi:10.1128/iai.00797-07.

32. Skountzou I, Quan FS, Jacob J, Compans RW, Kang SM. Transcutaneous immunization with inactivated influenza virus induces protective immune responses. Vaccine 2006;24:6110-19. doi:10.1016/j.vaccine.2006.05.014.

33. Anjuere F, George-Chandy A, Audant F, Rousseau D, Holmgren J, Czerkinsky C. Transcutaneous immunization with cholera toxin B subunit adjuvant suppresses IgE antibody responses via selective induction of Th1 immune responses. J Immunol 2003;170:1586-92.

34. Hemmi H, Takeuchi O, Kawai T, Kaisho T, Sato S, Sanjo H, Matsumoto M, Hoshino K, Wagner H, Takeda K, Akira S. A Toll-like receptor recognizes bacterial DNA. Nature 2000;408: 740-5. doi:10.1038/35047123.

35. Miller LS, Sorensen OE, Liu PT, Jalian HR, Eshtiaghpour D, Behmanesh BE, Chung W, Starner TD, Kim J, Sieling PA, Ganz T, Modlin RL. TGF-alpha regulates TLR expression and function on epidermal keratinocytes. J Immunol 2005;174:6137-43.

36. Ozel M, Hoglund S, Gelderblom HR, Morein B. Quaternary structure of the immunostimulating complex (iscom). J Ultrastruct Mol Struct Res 1989;102:240-8. doi:10.1016/0889-1605(89) 90018-9.

37. Ghochikyan A, Mkrtichyan M, Petrushina I, Movsesyan N, Karapetyan A, Cribbs DH, Agadjanyan MG. Prototype Alzheimer's disease epitope vaccine induced strong Th2-type antiAbeta antibody response with Alum to Quil A adjuvant switch. Vaccine 2006;24:2275-82. doi:10.1016/j.vaccine.2005.11.039.

38. Hoshino K, Takeuchi O, Kawai T, Sanjo H, Ogawa T, Takeda Y, Takeda K, Akira S. Cutting edge: Toll-like receptor 4 (TLR4)deficient mice are hyporesponsive to lipopolysaccharide: evidence for TLR4 as the Lps gene product. J Immunol 1999;162:3749-52.

39. van der Aar AM, Sylva-Steenland RM, Bos JD, Kapsenberg ML, de Jong EC, Teunissen MB. Loss of TLR2, TLR4, and TLR5 on Langerhans cells abolishes bacterial recognition. J Immunol 2007;178:1986-90.

40. Lebre MC, van der Aar AM, van Baarsen L, van Capel TM, Schuitemaker JH, Kapsenberg ML, de Jong EC. Human keratinocytes express functional Toll-like receptor 3, 4, 5, and 9. J Invest Dermatol 2007;127:331-41. doi:10.1038/sj.jid.5700530.

41. Kollisch G, Kalali BN, Voelcker V, Wallich R, Behrendt H, Ring J, Bauer S, Jakob T, Mempel M, Ollert M. Various members of the Toll-like receptor family contribute to the innate immune response of human epidermal keratinocytes. Immunology 2005;114:531-41. doi:10.1111/j.1365-2567.2005.02122.x.

42. Male D, Brostoff J, Roth DB, Roitt I. Immunology. Oxford: Elsevier; 2006.

43. Kool M, Soullie T, van Nimwegen M, Willart MA, Muskens F, Jung S, Hoogsteden HC, Hammad H, Lambrecht BN. Alum adjuvant boosts adaptive immunity by inducing uric acid and activating inflammatory dendritic cells. J Exp Med 2008;205:86982. doi:10.1084/jem.20071087. 
44. Lagergard T, Trollfors B, Claesson BA, Karlberg J, Taranger J. Determination of neutralizing antibodies and specific immunoglobulin isotype levels in infants after vaccination against diphtheria. Eur J Clin Microbiol Infect Dis 1992;11:341-5. doi:10.1007/BF01962074.

45. Bungener L, Geeraedts F, Ter Veer W, Medema J, Wilschut J, Huckriede A. Alum boosts TH2-type antibody responses to whole-inactivated virus influenza vaccine in mice but does not confer superior protection. Vaccine 2008;26:2350-9. doi:10.1016/j. vaccine.2008.02.063.

46. Scharton-Kersten T, Yu J, Vassell R, O'Hagan D, Alving CR, Glenn GM. Transcutaneous immunization with bacterial ADP- ribosylating exotoxins, subunits, and unrelated adjuvants. Infect Immun 2000;68:5306-13. doi:10.1128/IAI.68.9.53065313.2000.

47. Arigita C, Luijkx T, Jiskoot W, Poelen M, Hennink WE, Crommelin DJ, Ley P, Els C, Kersten GF. Well-defined and potent liposomal meningococcal B vaccines adjuvated with LPS derivatives. Vaccine 2005;23:5091-8. doi:10.1016/j.vaccine.2005. 06.001 .

48. Lee YH, Shin DW, Lee JH, Nam HW, Ahn MH. Vaccination against murine toxoplasmosis using recombinant Toxoplasma gondii SAG3 antigen alone or in combination with Quil A Yonsei Med J 2007;48:396-404. doi:10.3349/ymj.2007.48.3.396. 